\title{
QUAIS ADAPTAÇÕES ESTRUTURAIS SÃO MAIS EFICIENTES CONTRA HERBIVORIA: ESPINHOS OU TRICOMAS?
}

\section{ARTIGO ORIGINAL}

CARDOSO, Thâmara Chaves ${ }^{1}$

CARDOSO, Thâmara Chaves. Quais adaptações estruturais são mais eficientes contra Herbivoria: espinhos ou Tricomas? Revista Científica Multidisciplinar Núcleo do Conhecimento. Ano 04, Ed. 06, Vol. 01, pp. 05-15 Maio de 2019. ISSN: 2448-0959

\section{RESUMO}

Apesar de bastante explorado, o presente trabalho torna-se bastante relevante uma vez que, busca respostas para um questionamento a respeito da interação planta animal mais frequente da natureza. $O$ presente trabalho justifica-se pela necessidade de questionar qual das duas estruturas de defesa é mais eficiente contra ataques de herbivoria por ruminantes, os tricomas do cansanção ou os espinhos, do mandacaru, do xique-xique e da jurema - preta. O mesmo objetiva ainda averiguar como espinhos e tricomas conferem defesa à planta. Como resultados da pesquisa in loco pode-se perceber que apesar de atuarem de forma diferente as duas estruturas possuem igual eficiência na defesa dessas plantas.

Palavras chaves: Espinhos, Herbivoria, Ruminante, Tricomas.

\section{INTRODUÇÃO}

\footnotetext{
${ }_{1}$ Pós-Graduanda do curso de Especialização em Ecologia, da Universidade Federal do Piauí. Universidade Aberta do Brasil, Polo de Apoio Presencial de Canto do Buriti $-\mathrm{PI}$.
} 
Segundo Dourado-Pereira (2013), a herbivoria é um processo de interação ecológica em que animais ingerem partes da planta viva para seu alimento e nutrição. Grande parte dos animais, entre eles os ruminantes, possui uma alimentação restrita a vegetais, sendo chamados herbívoros, que podem se alimentar das plantas de diversas maneiras e intensidades (HERRERA, MEDRANO, SÁNCHEZ-LAFUENT; GARCÍA; GUITIÁN \& MANZANEDA, 2002).

Considerada a interação planta/animal mais frequente na natureza (WEIS, 1992), esse fenômeno apesar de necessário para a nutrição de organismos herbívoros, afeta segundo alguns autores, o desenvolvimento e o crescimento das plantas. De acordo com Pinto-Coelho (2000) os herbívoros podem comprometer o crescimento, a reprodução e a sobrevivência das plantas.

Apesar de Ricklefs (2003) afirmar que o consumo por herbivoria raramente ultrapasse $10 \%$ da biomassa vegetal de uma floresta, para Silva (2012) essa perda geralmente é maior do que a própria capacidade de distribuição e reprodução das plantas, que ainda assim, precisam manter-se disponíveis para o consumo intenso dos herbívoros.

Como resposta à herbivoria, relação com benefício unilateral, diversas espécies de plantas desenvolveram diferentes adaptações anti-herbivoria (SINIMBU, ZATZ, ROSA \& COSTA, 2008). Muito diferente do que se pensava, as plantas não são seres totalmente sésseis. Elas possuem plena capacidade de reação a estímulos, como a intensidade de luz, a quantidade de água ou a presença de algumas substâncias nas redondezas e até mesmo à presença de animais. (PINHEIRO; SANDRONI; LUMMERZHEIM; OLIVEIRA, 1999).

Como as plantas estão constantemente expostas, desenvolveram ao longo do processo evolutivo mecanismos de defesa contra estes agentes externos, e consequentemente contra o processo de herbivoria (RICKLEFS, 2003). Esse processo de acordo com Combes (1946) pode ser definido como adaptação, que é o conjunto de modificações provocadas na constituição de um organismo pela ação contínua de um meio diferente daquele onde, inicialmente, este se desenvolveu ou seus ascendentes. 
De modo similar, Chen (2008) coloca que as plantas possuem (entre outras formas de proteção) barreiras físicas e químicas que estão naturalmente presentes na planta antes do ataque de um herbívoro e geralmente são fatores determinantes para o consumo e palatabilidade dos ramos, folhas e outras partes da planta (COLEY; BRYANT, CHAPIN, 1985).

Os espinhos, por exemplo, estão relacionados com a função de defesa de uma planta, evitando que ela sofra ataques. Eles são estruturas ricas em lignina e, portanto, bastante rígidas (STRAUSS \& ZANGERL, 2002). Um exemplo de plantas que possuem essa adaptação são as cactáceas, como mandacaru (Cereus jamacaru), xique-xique (Pilosocereus gounellei) e jurema-preta (Mimosa tenuiflora).

Tricomas foliares também exercem um papel fundamental na defesa de plantas. Os tricomas são estruturas uni ou multicelulares, glandulares ou não; os glandulares podem estar presentes tanto na face inferior quanto na superior da lâmina foliar (RIBEIRO, HOPKINS; VICENTINI; SOTHERS; COSTA; BRITO; SOUZA; MARTINS; LOHMANN; ASSUNÇÃO; PEREIRA; SILVA; MESQUITA \& PROCÓPIO, 1999) Eles são apêndices semelhantes a fios de cabelo que se estendem desde a epiderme até tecidos aéreos (LEVIN, 1973). De acordo com Maia-Silva; Silva; Hrncir; Queiroz \& Imperatriz-Fonseca (2005) em várias espécies ou variedades há uma correlação negativa entre a densidade de tricomas e as respostas de alimentação de animais.

O cansanção (Cnidosculus vitifolius) é um exemplo de planta que usa tricomas na sua defesa contra os predadores, uma combinação de defesa mecânica e química. Os tricomas existentes nas folhas do cansanção são reservatórios de venenos, cuja química inclui as aminas, serotonina, histamina e acetilcolina. Elas provocam a sensação de queimadura ao toque com a pele, bastando para tanto o simples contato com seus pelos, ao pé dos quais há uma cápsula com o líquido agressivo (MUENSCHER, 1958).

Assim, o presente trabalho pretende verificar através de pesquisa bibliográfica e de campo se as plantas urticantes são mais eficientes contra os ataques dos predadores quando comparadas às plantas que possuem somente espinhos (cactáceas), 
conforme os seguintes objetivos: 1) averiguar qual grupo de plantas é mais resistente à herbivoria por ruminantes, 2) compreender como ocorre o processo de herbivoria, 3) observar como espinhos das cactáceas servem de defesa à planta, 4) investigar como os pelos do cansanção conferem proteção à planta e 5) procurar entre dois grupos de ruminantes (Bos taurus e Capra aegagrus hircus) quais evitam a herbivoria em cada tipo de planta aqui considerada. Supõe-se que as plantas urticantes sejam mais eficientes que às plantas espinhosas.

\section{MATERIAIS E MÉTODOS}

\section{1 ÁREA DE ESTUDO}

O estudo foi realizado numa área de $10.000 \mathrm{~m}^{2}$ na localidade Vaquejador, município de Canto do Buriti, Piauí (Figura 1). O clima da área é Tropical semiárido quente, com duração do período seco de sete a oito meses e as chuvas concentram-se nos meses de janeiro a março. O município é banhado pelo Rio Itaueira, lagoa Grande e riachos Cajazeiras, das Almas e Sambito. O solo é do tipo latossolo vermelho-amarelo podzólico associado a solos litólicos indiscriminados (IBGE, 1990). A vegetação é típica da zona de ecótono entre caatinga e cerrado.

De acordo com o IBGE (2008) existem 4.334 cabeças de gado caprino e 16.190 de gado bovino no município de Canto do Buriti. De acordo com pesquisa de campo, os produtores rurais criam seus animais de forma semiextensiva, destinados ao corte e à produção de leite. Poucos produtores que criam seus animais de forma extensiva foram encontrados.

\subsection{COLETA DOS DADOS}

O levantamento dos dados foi realizado durante os meses de julho e agosto, uma vez que durante a seca ocorre escassez de alimentos e o grupo de ruminantes investigado não possuíam muitas fontes de alimento. 
Para análise da herbivoria, foram levados em consideração somente indivíduos adultos das plantas que apresentam espinhos e/ou tricomas, uma vez que essas estruturas já estão bem desenvolvidos. Também foram utilizadas e registradas pesquisas em trabalhos publicados na área, como Dourado-Pereira (2013); Araújo; Holanda Júnior, Kill; Campanha \& Gomes (2008); Chen (2008); Ribeiro, Hopkins; Vicentini; Sothers; Costa; Brito; Souza; Martins; Lohmann; Assunção; Pereira; Silva; Mesquita \& Procópio (1999); Cavalcanti \& Resende (2004).

Além disso, foram entrevistados pecuaristas de gado bovino e caprinos em regime extensivo, e semi-intensivo, para complementação das informações levantadas na bibliografia. Utilizou-se fita métrica, GPS e câmera fotográfica para demarcação das parcelas.

$\mathrm{Na}$ área demarcada foram instaladas 16 parcelas (10 $\mathrm{m} \times 10 \mathrm{~m}$ ), à direita de uma trilha pré-existente, em uma área particular de passagem de gado bovino e caprino (Figura 1). Nenhuma ação foi realizada para alterar o comportamento normal dos animais. Foram sorteadas oito parcelas, onde foram contados todos os indivíduos das populações de Cereus jamacaru, Cnidosculus vitifolius, Mimosa hostilis, M. tenuiflora e Pilosocereus gounellei. A amostragem consistiu em observar pelo método visual se alguma planta apresentou sinais de forrageamento por bovinos e caprinos, identificando e quantificando esses indivíduos.

Foi pré-estabelecido um percentual de área consumida por herbívoros, utilizando o método de Dirzo e Domingues (1995) a partir das seguintes categorias: $0=$ sem herbivoria; 1 = até $12,5 \%$ da superfície perdida; $2=$ até $25 \%$; $3=$ até $37,5 \% ; 4=$ até $50 \% ; 5=$ até $62,5 \% ; 6=75 \% ; 7=$ até $87,5 \% ; 8=$ até $100 \%$ de superfície perdida. 
Figura 1. Área de estudo, comunidade Vaquejador, município de Canto do Buriti, Piauí.

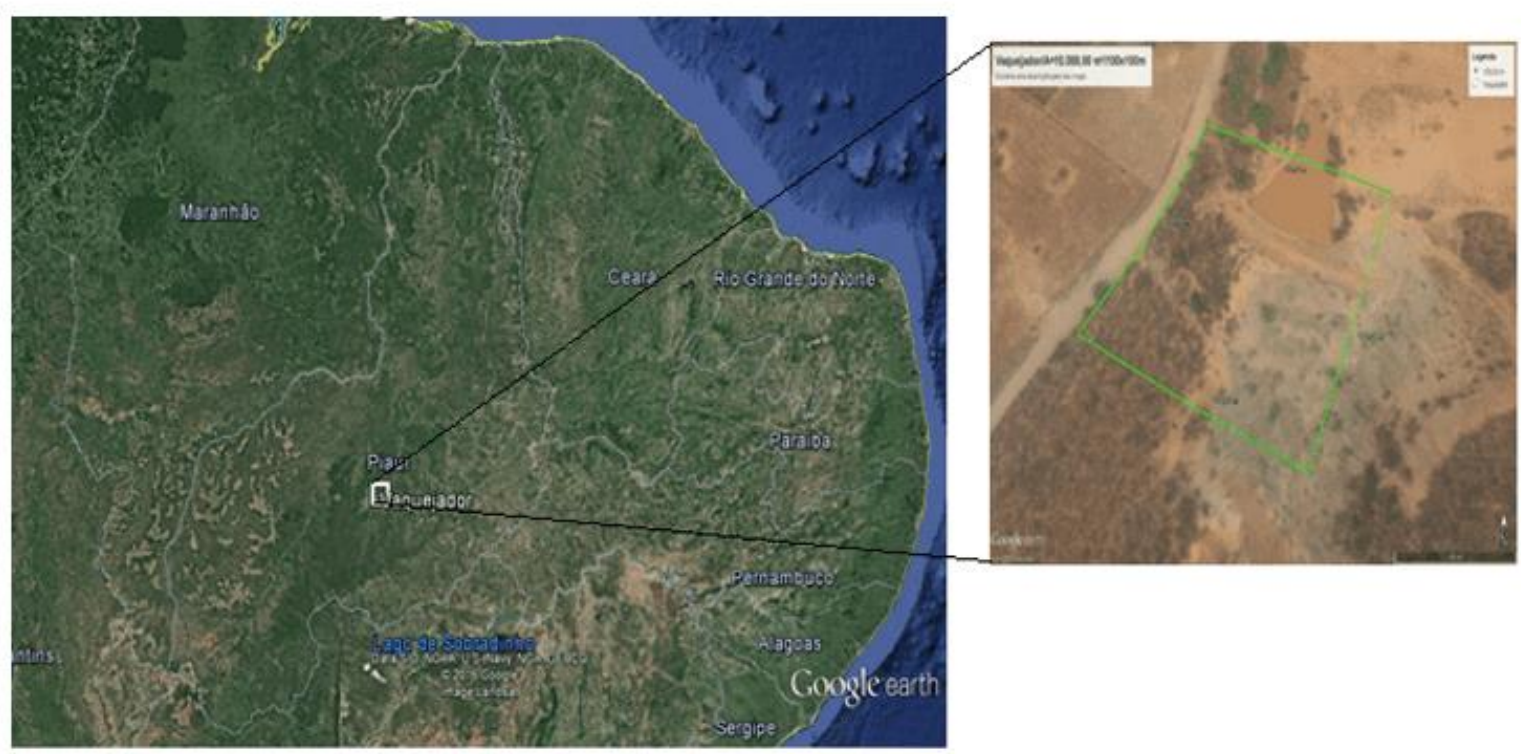

(Fonte: GOOGLE EARTH).

\section{RESULTADOS E DISCUSSÃO}

As parcelas demarcadas com fita amarela foram sorteadas utilizando o site de sorteio de números aleatórios: www.randomnumbergenerator.intemodino.com. Os sorteados foram $1,5,8,9,12,13,14,16$. Nelas foram registrados 129 indivíduos de plantas com tricomas ou espinhos, distribuídos em: 63 indivíduos de cansanção (Cnidosculus vitifolius), 37 de xique-xique (Pilosocereus gounllel), 26 de mandacarú (Cereus Jamacaru) e três da jurema-preta (Mimosa tenuiflora). 
Figura 2. Espécies investigadas no presente estudo

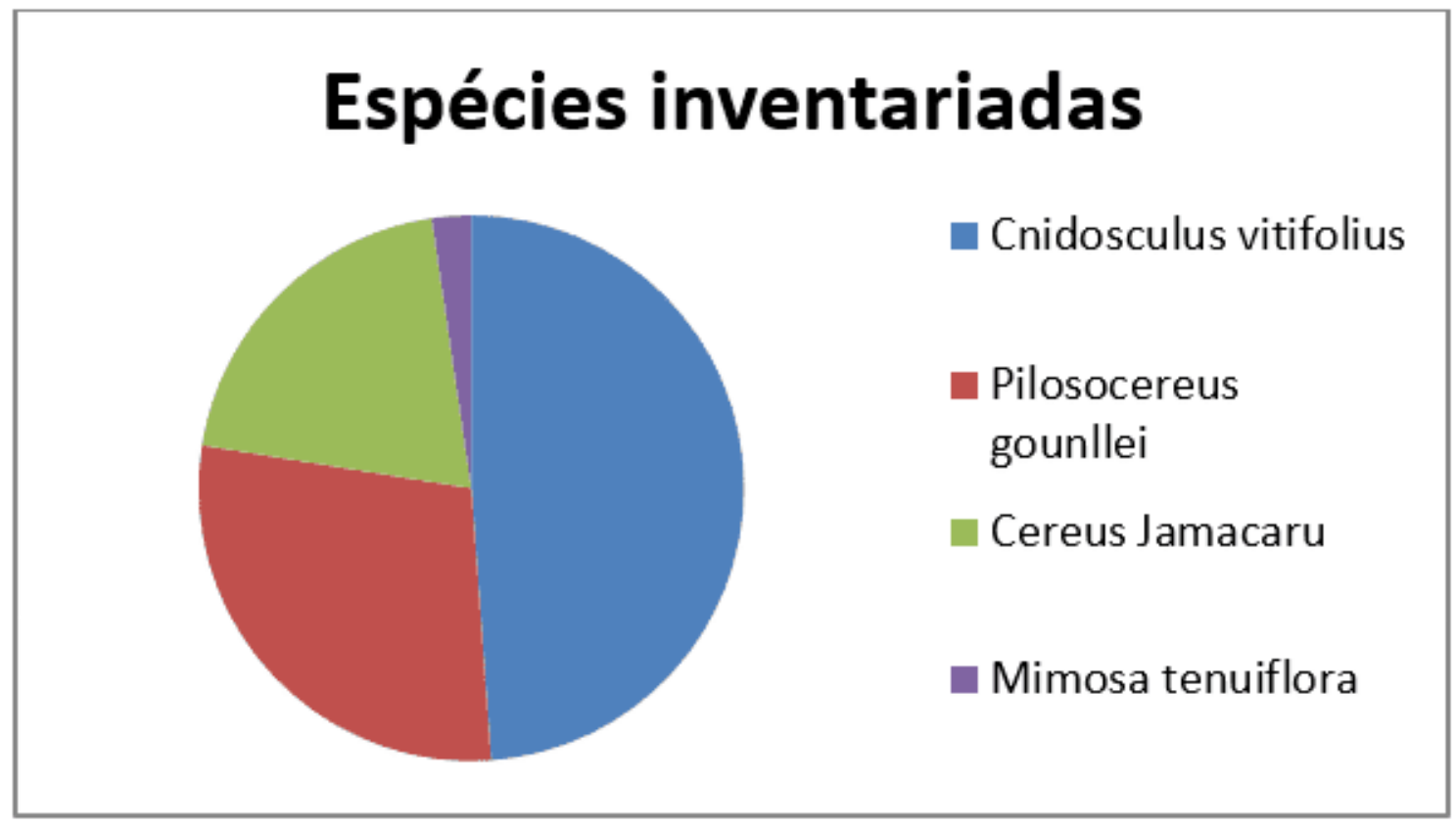

Fonte: (CARDOSO, 2016).

Cnidosculus vitifolius pertence à família Euphorbiaceae e possui tricomas urticantes e vesiculantes. Conhecida popularmente como cansanção, ela possui pelos que quando tocados, provocam fortes dores localizadas, urticárias e até, em raros casos, desmaios (MUENSCHER, 1958). O xiquexique (Pilosocereus gounellei) é uma Cactaceae de tronco ereto com galhos laterais afastados e com uma curva ampla em direção ao solo. Seus ramos são compostos por espinhos rígidos e de coloração verde-opaca. (Cavalcanti, 2004)

Gomes (1977) afirma que Pilosocereus gounellei desenvolve-se apenas nas áreas mais secas da região semiárida do Nordeste, em solos rasos, sobre rochas e se multiplica regularmente, cobrindo extensas áreas da caatinga. Segundo o mesmo autor, sua distribuição ocorre principalmente nos estados do Ceará, Rio Grande do Norte e Bahia. No entanto, Lima (1998) aponta que o xiquexique ocorre nas caatingas de outros estados do Nordeste como o Piauí. 
O mandacaru (Cereus Jamacaru) de acordo com Barbosa (1998) é uma das plantas mais características do semiárido nordestino é um cacto de porte arbóreo de tronco muito grosso e ramificado e pode atingir até três metros de Altura. Segundo Araújo; Holanda Júnior, Kill; Campanha \& Gomes (2008) o mandacaru é uma cactácea de formato colunar, tronco ramificado e coloração verde, com espinhos amarelados que podem medir até $20 \mathrm{~cm}$, é considerada a planta mais importante da Caatinga.

A jurema-preta (Mimosa tenuiflora) é uma leguminosa típica da caatinga, que apresenta grande quantidade de espinhos em seus ramos. Seu tronco tem casca de cor castanho-escura e ramos de cor castanho-avermelhada. Podendo também ser encontrada na zona de ecótono entre a caatinga e o cerrado. Bastante resistente à seca, esta espécie possui, de acordo com Gariglio; Sampaio; Cestaro \& Kageyama (2010) grande capacidade de tolerância às condições extremas do semiárido. Floresce durante um longo período do ano, porém sua predominância ocorre durante a estação seca. É uma planta de formação arbórea que geralmente apresenta baixos coeficientes de digestibilidade. Isto se deve, provavelmente, às mais elevadas concentrações de lignina e aos compostos químicos secundários, como o tanino. (GONZAGA NETO BATISTA \& CARVALHO, 2001).

Quanto à análise de herbivoria, todos os indivíduos de Cnidosculus vitifolius e Pilosocereus gounellei, Cereus jamacaru e Mimosa tenuiflora se enquadraram na categoria zero, ou seja, nenhum espécime possuía sinal de ter sido forrageado em nenhuma das parcelas montadas.

Entretanto, de acordo com os agricultores da região, na época de maior escassez pode acontecer herbivoria por caprinos nas cactáceas, apesar dos proeminentes espinhos. Segundo eles esses por raríssimas vezes alguns indivíduos desenvolveram a capacidade de retirar os espinhos utilizando seus chifres. Foram mencionados dois casos isolados também de animais que se alimentaram de cactáceas in natura, mas estes tiveram seus intestinos perfurados, de acordo com o agricultor entrevistado. Entretanto como regra geral mesmo nos períodos de extrema falta de alimento, os animais evitam tanto as plantas com espinhos quanto as com tricomas. 
Figura 3. Espécies investigadas no presente estudo: A) Mimosa tenuiflora B) Pilosocereus gounellei C) Cereus jamacaru D) Mimosa tenuiflora E) Cnidosculus vitifolius
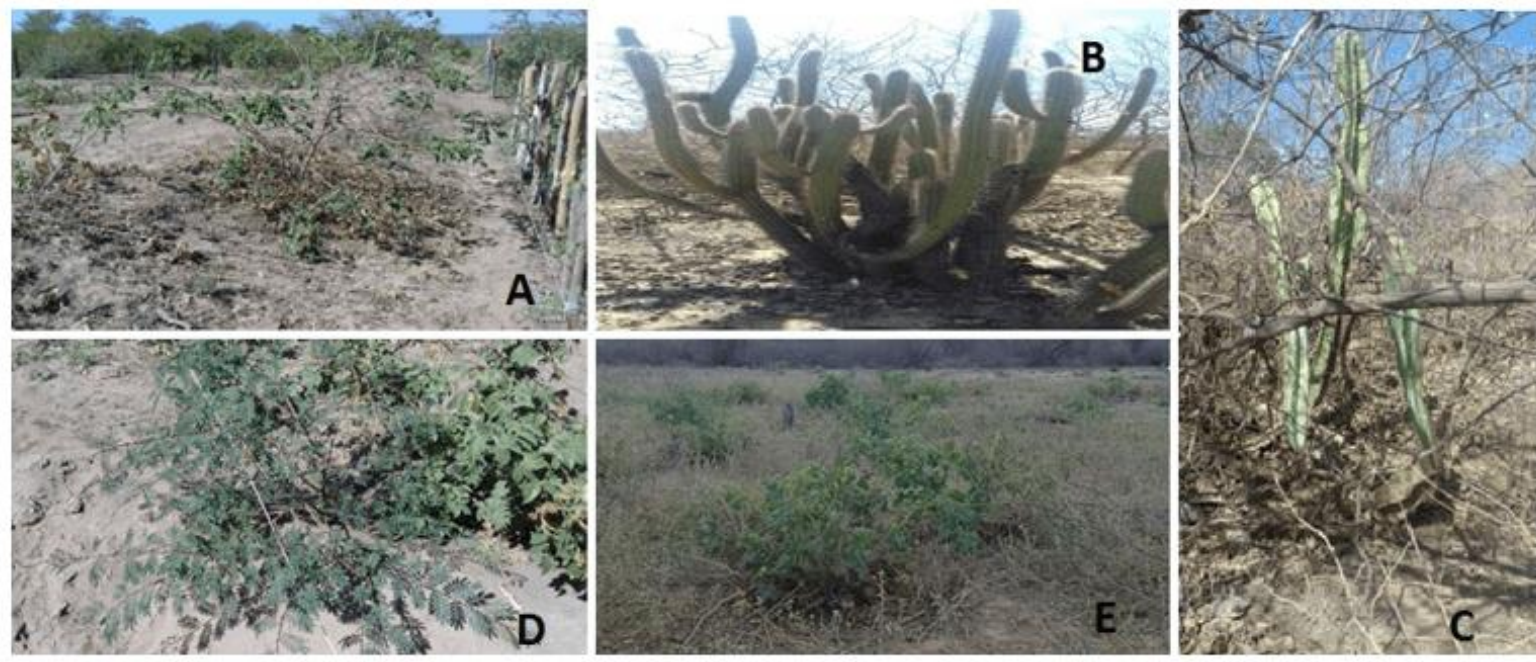

Fonte: (CARDOSO, 2016).

Segundo Cavalcanti \& Resende (2004), em pesquisas também desenvolvidas na Caatinga, nos períodos de seca prolongada diversas espécies de Cactaceae, como Cereus jamacaru e Pilosocereus gounelley, também são utilizadas como forrageiras pelos caprinos, entretanto estas são previamente preparadas pelos agricultores através do processo de queimada para enfraquecimento dos espinhos. Araújo; Holanda Júnior, Kill; Campanha \& Gomes (2008) também citam que o mandacaru, quando utilizado como forrageira, precisa ser picado e seus espinhos devem ser queimados para facilitar seu consumo pelos animais.

De acordo com Embrapa (2003) os caprinos se alimentam tanto da jurema-preta quanto da branca, entretanto eles dão preferência aos brotos novos e às vagens, não fazendo uso dos brotos adultos com espinhos desenvolvidos. Cabe aqui frisar que somente indivíduos adultos foram considerados para resultados no presente trabalho.

Em seu estudo com bovinos Dias et al. (2005), trabalhando com 16 espécies arbóreas incluindo a jurema-preta, constatou que esta apresentou o maior número de plantas sobreviventes e menos pastejadas. Segundo Nozella (2001), apesar do seu alto teor 
de proteína bruta (16\%), essa planta apresenta baixa digestibilidade pois apresenta altos níveis de tanino.

Jung e Allen (1995), em trabalho similar citam que a lignificação da parede celular pode limitar a digestão dos polissacarídeos por meio de três possíveis mecanismos: efeito tóxico dos componentes da lignina aos micro-organismos; impedimento físico causado pela ligação lignina-polissacarídeo, que limita o acesso das enzimas fibrolíticas e; a limitação da ação de enzimas hidrofílicas causada pela hidrofibicidade criada pelos polímeros de lignina.

Figura 4. A) Pegadas de gado bovino na área inventariada; B) Capra aegagrus hircus alimentando-se de Pilosocereus gounelley queimado por agricultores.
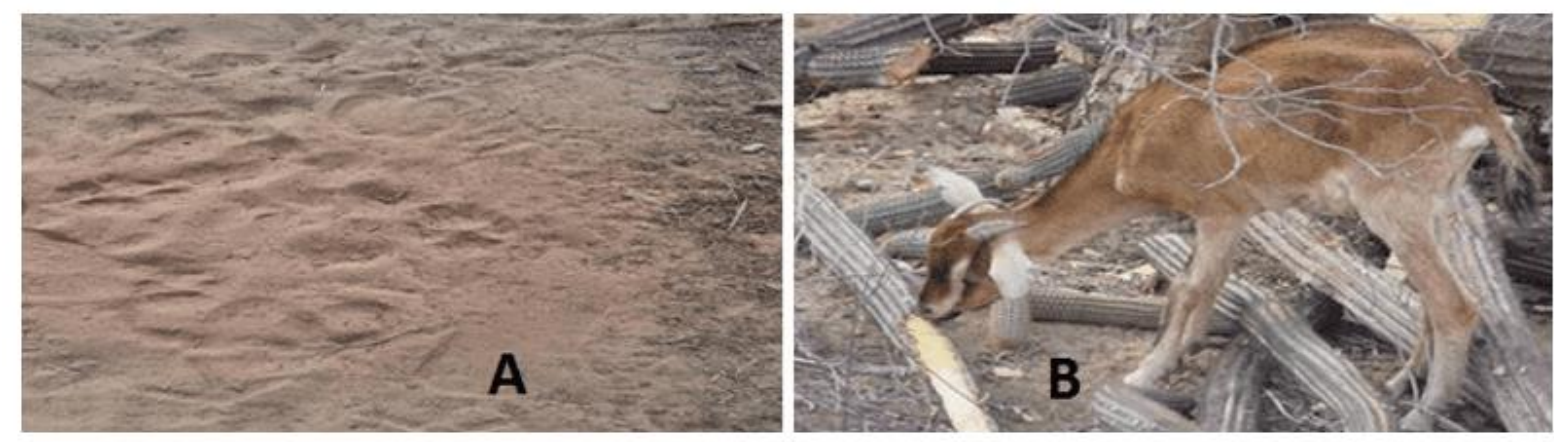

Fonte: belezadacaatinga.blogspot

\section{CONSIDERAÇÕES FINAIS}

Diferente da suposição inicial ficou demonstrado no presente estudo que ao comparar espinhos e tricomas quanto à sua eficiência na defesa contra a herbivoria, as duas estruturas possuem igual vantagem, deixando os dois grupos de plantas bastante resistentes à herbivoria por ruminantes, não sendo portando, forrageados por nenhum desses animais. Os espinhos, além de dificultarem o processo mastigatório, causam, através de seus componentes químicos, grande dificuldade de digestão. Os tricomas por causarem queimaduras pelo contato repelem imediatamente qualquer tentativa predatória. Finalmente, tanto espinhos quanto tricomas são altamente eficientes na sua defesa contra herbivoria. 


\section{REFERÊNCIAS}

ARAUJO, G. G. L; HOLANDA JÚNIOR, E. V. de; KIILL, L. H. P; CAMPANHA, M. M \& GOMES, T. O. 2008. Potencial forrageiro da caatinga na comunidade de Testa Branca, Uauá-BA. Petrolina: Embrapa Semi-Árido; Sobral: Embrapa Caprinos,.

BARBOSA, H. P., 1998. Tabela da composição de Alimentos do Estado da Paraíba "Setor Agropecuário". 2ª ed. FAPEP - UFPB. 221 p.

CAVAlCANTI, N. B. \& RESENDE, G. M. 2004. Plantas nativas da caatinga utilizadas pelos pequenos agricultores para alimentação dos animais na seca. In.: CONGRESSO NORDESTINO DE PRODUÇÃO ANIMAL, 3. Campina Grande. Anais... Campina Grande PE: Sociedade Nordestina de Produção Animal. CD-ROM.

CHEN, M. S. 2008. Inducible direct plant defense against insect herbivores: A review. Insect Science, Beijing, v.15, n. 2, p.101-114.

COLEY, P.D.; BRYANT, J.P.; CHAPIN, S.F. 1985. Resource Availability and Plant Antiherbivory Defense, Science, Washington, v.230, n.4728, p.895-899.

COMBES, R. 1946 La forme des végétaux et le milieu. A. Colin, Paris.

DIAS, P.F.; SOUTO, S.M.; FRANCO, A.A. 2005. Introdução e avaliação de leguminosas arbóreas em pastagens da baixada e região serrana do estado do Rio de Janeiro. Seropédica: Embrapa Agrobiologia, 2005. 24p. (Embrapa Agrobiologia. Boletim de Pesquisa e Desenvolvimento, 09)

DIRZO, R.; DOMINGUEZ. C. 1995. Plant-herbivore interactions in Mesoamerican tropical dry forest. In: BULLOCK, S. H.; MOONEY, H. A.; MEDINA, E. A. (eds.). Seasonally Dry Tropical Forests. Cambridge: Cambridge University Press, p. 304-325.

DOURADO \& PEREIRA, A. C. 2013. Herbivoria em espécies decíduas e perenes da Caatinga no Nordeste do Brasil. Itapetinga-BA: UESB,60p (Dissertação - 
Mestrado em Ciências Ambientais - Área de Concentração em Interação PlantaAnimal)

EMBRAPA. 2002. Manual do Produtor de Caprinos. Disponível em https://sistemasdeproducao.cnptia.embrapa.br/FontesHTML/AgriculturaFamiliar/Regi aoMeioNorteBrasil/Caprinos/alimentacao.htm. Acesso em 01 de agosto de 2016

GARIGLIO, MARIA AUXILIADORA; SAMPAIO, EVERARDO VALADARES DE SÁ BARRETTO; CESTARO, LUIS ANTÔNIO; KAGEYAMA, PAULO YOSHIO. 2010. Uso sustentável e conservação dos recursos florestais da Caatinga. Brasília: Serviço Florestal Brasileiro, p.368.

GIL, Antonio Carlos. 2002. Como elaborar projetos de pesquisa. 4a . Ed.- São Paulo: Atlas. (pg..41a 56).

GONZAGA NETO, S.; BATISTA, A.M.V.; CARVALHO, F.F.R. 2001. Composição química, consumo e digestibilidae "in vivo" de dietas com diferentes níveis de feno de catingueira (Caesalpinea bracteosa) fornecida para ovinos Morada Nova. Revista Brasileira de Zootecnia, v.30, n.2, p.553-562.

GONSALVES, Elisa Pereira. 2005. Conversas sobre iniciação a pesquisa cientifica. -4 a . Ed. Campinas, SP, Alínea.

GOMES, R. P. 1977. Forragens fartas na seca. 4 ed. São Paulo: Nobel,. 233p.

HERRERA, C. M.; MEDRANO, M.; REY, P. J.; SÁNCHEZ-LAFUENTE, A. M.; GARCÍA, M. B.; GUITIÁN, J. \& MANZANEDA, A. J. 2002. Interaction of pollinators and herbivores on plant fitness suggests a pathway for correlated evolution of mutualism- and antagonism-related traits. PNAS, Washington, v.99, n.26, p.1682316828.

IBGE. Aspectos Geográficos de Canto do Buriti. Disponível em:<http://www.cidades.ibge.gov.br.html> Acessado em: 15 de agosto de 2016. 
JUNG, H. G. \& ALLEN, M. S. 1995. Characteristics of plant cell wall affecting intake and digestibility of forages by ruminants. Journal of Animal Science, v. 73, p. 2774-2790.

LEVIN, D.A. 1973. The role of trichomes in plant defense. Quarterly Review of Biology, 48: 3-15.

LIMA, G. F. C. 1998. Alternativas de seleção e manejo de volumosos forrageiros para atividade leiteira no Nordeste. In.: SIMPÓSIO O AGRONEGÓCIO DO LEITE NO NORDESTE: alternativas tecnológicas e perspectivas de mercado, 1998, Natal. Anais... Natal: EMPARN/FIERN/SENAI, p. 192.

MUENSCHER, W.C. 1958. Euphorbiaceae. New York, The Macmillan Company.

NOZELLA, E.F. 2001. Determinação de taninos em plantas com potencial forrageiro para ruminantes. 58p. Tese de Mestrado apresentado no CENAUniversidade de São Paulo- Piracicaba.

Números Aleatórios. Disponível em www.randomnumbergenerator.intemodino.com. Acesso em 16 de agosto de 2016.

PINTO-COELHO, R.M. 2000. Fundamentos em ecologia. Artmed Editora, São Paulo.

RICKLEFS. R. E. 2003. A economia da natureza. 5a Ed. Guanabara Koogan S. A. Rio de JANEIRO.

MAIA-SILVA, CAMILA; SILVA, CLÁUDIA INÊS DA; HRNCIR MICHAEL; QUEIROZ, RUBENS TEIXEIRA DE \& IMPERATRIZ-FONSECA, VERA LUCIA. 2012. Guia de plantas: visitadas por abelhas na Caatinga. $1^{\circ}$ ed. Fortaleza, CE: Editora Fundação Brasil Cidadão.

SINIMBU, GEORGIA; ZATZ, CAMILA; ROSA, CASSIANO S. \& COSTA, ÚRSULA S. DA. 2008. Pelos, Por que tê-Los: Tricomas protegem a planta contra Herbivoria? 
Disponível

em

http://pdbff.inpa.gov.br/cursos/efa/livro/2008/pdf/dimona/po1grupo4.pdf. Acesso em 16 de agosto de 2016.

PINHEIRO, M.M.; SANDRONI, M.; LUMMERZHEIM, M.; OLIVEIRA, D.E., 1999, A defesa das plantas contra as doenças. Ciência Hoje, 147: 1-11.STRAUSS, S.Y. \& A.R.

ZANGERL. 2002. Plant-insect interactions in terrestrial ecosystems, pp. 107- 130. Em: Plant-animal interactions: an evolutionary approach (C.M. Herrera \& O. Pellmyr, eds). Blackwell Science, Cornwall.

Enviado: Julho, 2018

Aprovado: Julho, 2019 